NASZA DERMATOLOGIA Online OUR DERMATOLOGY Online

Source of Support: Nil

Competing Interests: None

\section{CLINICO - HISTOPATHOLOGICAL CORRELATION IN LEPROSY: A TERTIARY CARE HOSPITAL BASED STUDY}

\author{
Deeptara Pathak Thapa, Anil Kumar Jha
}

Department of Dermatology, Nepal Medical College and Teaching Hospital, Kathmandu, Nepal

Corresponding author: Ass. Prof. Deeptara Pathak Thapa

drdeeptarapathak@yahoo.com

\begin{abstract}
Introduction: Leprosy is a chronic infectious disease affecting mainly cutaneous and peripheral nervous system. Histopathology is an important tool to diagnosis leprosy in situation where it mimics other clinical condition. This study was conducted to know the correlation between clinical and histopathological diagnosis of Leprosy.

Material and Methods: This was a retrospective study and patients were enrolled in whom leprosy was clinically diagnosed or suspected and histo-pathological examinations were carried upon.

Results: A total of 71 patients were studied. Of them 48 patients $(67.6 \%)$ were males and rest $23(32.39 \%)$ patients were females. Mean age of patients at presentation was $37.85+/-2.021$ years. Clinically in 42 patients $(59.1 \%)$ type of leprosy could not be specified. Borderline tuberculoid was diagnosed in 7 patients $(9.8 \%)$, Tuberculoid in 6(8.5\%), Relapse in 3(4.2\%), lepromatous in 6(8.5\%) and Borderline, borderline lepromatous 1(1.4), Indeterminate 1 patient (1.4\%). In $7 \%$ cases, Hansens disease was considered as differential diagnosis along with other clinical conditions. In $47 \%$ cases, data was not available. On histopathological evaluation on skin biopsies, epidermal changes seen were $29.5 \%$. Of the total 71 patient, dermal changes seen were granuloma (42\%), dermal infiltrate (11\%), adnexal infiltrate (7\%), nerve infiltrate (11\%), adnexal with nerve infiltrate $(6 \%)$, perivascular with adnexal infiltrate $(20 \%)$ and nonspecific (3\%). Dermal infiltrates in $46.4 \%$ cases constituted of lympho-histiocytes. In 48 patients (69\%) leprosy was histopathologically confirmed and in rest $31 \%$ cases diagnoses was non-specific in 20 patients (28.1\%), vasculitis, Dariers and Fungal infection 1 patient each (1.4\%). Borderline Tuberculoid (BT) and TT was the most common diagnosis among leprosy patients around $29.2 \%$ each, followed by Indeterminate $25 \%$, LL $8.3 \%$, BL and and Pure neural $4.1 \%$ each. When clinical diagnosis and histopathological diagnosis was correlated it was found that the parity was seen in TT as $66.6 \%$, BT $42.9 \%$, LL $16.7 \%$. Where Hansen's disease was kept as differential diagnosis two patients had leprosy.

Conclusion: The study being retrospective the uniformity in clinical diagnosis and histopathological evaluation couldnot be assessed. With the limitations this study still give information about the importance of histopathology to diagnose Leprosy and for proper treatment category and decrease the burden of the disease in the society.
\end{abstract}

Key words: histopathology; leprosy; granuloma

Deeptara Pathak Thapa, Anil Kumar Jha: Clinico - histopathological correlation in leprosy: a tertiary care hospital based study. Our Dermatol Online. 2013; 4(3): 294-296

\section{Introduction}

Leprosy is a disease affecting mainly skin and peripheral nervous system but can also affect other organs and one of the most common public health problems in this country [1]. In Nepal though Leprosy has been on decline with government declaring elimination of leprosy after achieving a prevalence rate of 0.89 per 10,000 persons, still the disease is prevailing [2]. According to Ridley \& Jopling classification it has been classified on the basis of clinical, histopathological and immunological status of the host. Due to its clinical diversity as well as its ability to mimic other diseases sometimes leprosy is difficult to diagnose clinically. In such catch-22 situations, histopathological examination is a helpful diagnostic tool to confirm diagnosis. This study was conducted to know the correlation between clinical and histopathological diagnosis of
Leprosy in a tertiary care hospital based scenario.

\section{Material and Methods}

We conducted a retrospective study in outpatient department of Dermatology, Nepal Medical College and Teaching hospital. We enrolled patients between 2008 and 2012, in whom leprosy was clinically diagnosed or suspected and histo-pathological examinations were carried upon. The data were retrieved from the records maintained in the department including age, sex, residence, clinical diagnosis, histopathological findings and treatment. To determine clinico- histopathological correlation of skin biopsies in leprosy, statistical evaluation SPSS version 11.5 was used. Chi square test and Fishers exact test was used for statistical significance and $\mathrm{p}$ value $<0.05$ was considered significant. 


\section{Results}

A total of 71 patients were studied. Of them 48 patients (67.6\%) were males and rest $23(32.39 \%)$ patients were females. Youngest patient was 12 years old and oldest was 80 years at presentation; however mean age of patients at presentation was $37.85+/-2.021$ years. Clinically, in 42 patients $(59.1 \%)$ type of leprosy could not be specified (Tabl. I). Borderline tuberculoid was diagnosed in 7 patients $(9.8 \%)$, Tuberculoid in $6(8.5 \%)$, Relapse in $3(4.2 \%)$, lepromatous in $6(8.5 \%)$ and Borderline, borderline lepromatous 1(1.4), Indeterminate 1 patient (1.4\%).

In $7 \%$ cases, Hansens disease was considered as differential diagnosis along with other clinical conditions. Slit skin smear was positive in 4 cases $(5.6 \%)$ and negative in $25(35 \%)$. PAS stain was positive in 1 patient $(1.4 \%)$. Fite stain was positive in 2 patients (2.8\%) but was negative in $9.8 \%$ cases. In $47 \%$ cases, data was not available.

On histopathological evaluation on skin biopsies, epidermal changes seen were thinning $(11.26 \%)$, hyperkeratosis $(9.8 \%)$, acanthosis (7\%) and cleft (1.4\%) however it was normal in $70.4 \%$ patients Interface dermatitis was seen in $2.8 \%$ cases and grenz zone in $7 \%$ cases but in $90.1 \%$ interface changes were not specified. Of the total 71 patient, dermal changes seen were granuloma (42\%), dermal infiltrate $(11 \%)$, adnexal infiltrate $(7 \%)$, nerve infiltrate $(11 \%)$, adnexal with nerve infiltrate $(6 \%)$, perivascular with adnexal infiltrate (20\%) and nonspecific (3\%). Dermal infiltrates in $46.4 \%$ cases constituted of lympho-histiocytes followed by lymphocyte (39.4\%), epitheloid cells (8.4\%) and foamy cells (8.4\%) but was not mentioned in $3 \%$ cases. Of the 4 cases that had infiltrates seen in subcutaneous layer, 2 had giant cells and 1 each had lymphocytes and mixed cellular infiltrates. In 48 patients (69\%) leprosy was histopathologically confirmed and in rest $31 \%$ cases diagnoses was non-specific in 20 patients $(28.1 \%)$, vasculitis, Dariers and Fungal infection 1 patient each (1.4\%). Borderline Tuberculoid (BT) and TT was the most common diagnosis among leprosy patients around $29.2 \%$ each, followed by Indeterminate $25 \%$, LL $8.3 \%$, $\mathrm{BL}$ and and Pure neural $4.1 \%$ each. When clinical diagnosis and histopathological diagnosis was correlated it was found that the parity is seen in TT as $66.6 \%$, BT $42.9 \%$, LL $16.7 \%$, where it was not classified 69\%, relapse 66.7 and Hansens as Differentials $40 \%$. There was no parity seen in BL, Pure Neural and Indeterminate. There were some interesting findings like indeterminate cases were more histopathologically diagnosed. One LL case was found to be TT histopathologically. Clinically where diagnosis was not specified, $69 \%$ patients had leprosy. Where Hansen's disease was kept as differential diagnosis two patients had leprosy. Details of the correlation between clinical and histopathological diagnosis is given in Table II.

\begin{tabular}{|l|l|}
\hline \multicolumn{1}{|c|}{ Clinical Diagnosis } & \multicolumn{1}{c|}{ Numbers (\%) } \\
\hline TT & $6(8.5)$ \\
\hline BT & $7(9.9)$ \\
\hline BL & $1(1.4)$ \\
\hline LL & $6(8.5)$ \\
\hline Pure neural & $0(0)$ \\
\hline Intermediate & $1(1.4)$ \\
\hline Not Classified & $42(59.2)$ \\
\hline Relapse & $3(4.2)$ \\
\hline Hansens as Differentials & $5(7.0)$ \\
\hline Table I. Clinical diagnosis & \\
\hline
\end{tabular}

\begin{tabular}{|c|c|c|c|c|c|c|c|c|}
\hline \multirow[t]{2}{*}{ Clinical Groups } & \multicolumn{8}{|c|}{ Histologic Groups } \\
\hline & TT & BT & BL & $\mathbf{L L}$ & Intermediate & Pure neural & $\begin{array}{c}\text { Other than } \\
\text { Hansens }\end{array}$ & \% Parity \\
\hline TT & 4 & 1 & 0 & 0 & 0 & 0 & 1 & 66.6 \\
\hline BT & 3 & 3 & 0 & 0 & 0 & 0 & 1 & 42.9 \\
\hline $\mathrm{BL}$ & 0 & 0 & 0 & 0 & 1 & 0 & 0 & 0 \\
\hline LL & 1 & 0 & 0 & 1 & 1 & 0 & 3 & 16.7 \\
\hline Pure neural & 0 & 0 & 0 & 0 & 0 & 0 & 0 & 0 \\
\hline Intermediate & 0 & 0 & 0 & 0 & 0 & 0 & 1 & 0 \\
\hline Not Classified & 5 & 9 & 2 & 1 & 10 & 2 & 13 & 69 \\
\hline Relapse & 0 & 1 & 0 & 1 & 0 & 0 & 1 & 66.7 \\
\hline Hansens as Differentials & 1 & 0 & 0 & 1 & 0 & 0 & 3 & 40 \\
\hline Total & 14 & 14 & 2 & 4 & 12 & 2 & 23 & \\
\hline
\end{tabular}

Table II. Correlation between clinical and Histopathological diagnosis $\mathbf{P}=0.034$ according to pearson's rank correlation 


\section{Discussion}

In developing countries like Nepal, Leprosy is still one of the major public health problems. The Ridley jopling classification is a standard classification to diagnosis leprosy which is based on clinical, histopathological and immunological status of the host. In our study clinicopathological correlation was found in TT as $66.6 \%$, BT $42.9 \%$, LL $16.7 \%$ and where it was no classified according to Ridley Joplings criteria found to be $69 \%$ which means clinically where hansens was suspected histopathologically it was confirmed and these percentage of patients were treated and rendered noninfectious. On statistical analysis it was found to be statistically significant ( $\mathrm{P}$ value 0.034 ). Pandya et al found parity in $68.3 \%$, Moorthy et al in $62.63 \%$ [4], Kar et al in $70 \%$, Jerath et al in $68.5 \%$ and Mathur et al in $80.4 \%$ [2-6,11-13]. In most of these studies like moorthy et al, Kar et al and Jerath et al found parity in TT pole and Mathur et al in LL pole [14]. Our study also found parity in TT and BT. Jha et al also found parity in BT cases [7]. There was lack of uniformity in clinical impression and clinical details in our study. Slit skin smear report was not available in $40 \%$ and in $47 \%$ fite stain was not mentioned. In histopathology too Ridley jopling classification was not used. Interface changes were not interpreted in $90.1 \%$. In dermal changes none of the reports described about exact location of the granuloma, whether infiltrating appendages or not. In $53 \%$, location of the dermal infiltrate were not mentioned. There were some interesting findings in our study like one case of LL was found to be histopathologically TT. In histopathological evaluation it was found that epitheloid giant cell granuloma was seen. But it was not mentioned it was eroding epidermis or not. Most of the indeterminate cases was diagnosed histopathologically where periadnexal, perineural infiltrate were seen. In two patients even granuloma was also found and histopathologically it doesn't fit in Indeterminate type. Moorthy et al [4] also found indeterminate type more histologically than clinically. Due to non specific histology it becomes difficulty to diagnose IL type. It also depends upon various factors like depth of biopsy, quality of sections, and number of sections examined and staining method including both H\&E and acid fast stain $[4,8-10]$. Clinically where diagnosis was not specified $69 \%$ had histopathological diagnosis of leprosy. Where Hansens disease was kept as differential diagnosis two patients had leprosy. Most of the above studies have strictly followed Ridley jopling classification but in our study it was not but still the percentage of parity is similar in their studies compared to our study. It is therefore important to have histopathological evaluation in suspected case of leprosy mostly in the Borderline groups and where slit skin smears are negative. Clinical information like site of lesion, type of lesion, nerve involvement, sensory impairment, treatment history along with immunological status of patients is very important for the pathologist to correlate histopathologically. Histopathological diagnosis also depends on various factors like size of biopsy specimen, age of lesion, depth of biopsy, quality of section and very important interobserver variation has a role in clinico-pathological evaluation [15].

\section{Conclusions}

There are certain limitations in our study. The study being retrospective the uniformity in clinical diagnosis and histopathological evaluation could not be assessed. With the limitations this study still give information about the importance of histopathology as in few of the cases where diseases was not specified or Hansens was kept as differential diagnosis, histopathologically different poles of hansens disease as well as others like Dariers or fungal was evaluated and is important for treatment point of view. Sometimes it is difficult on clinical grounds due to its varied presentation and could mimic with other diseases therefore histopathological examination is needed to confirm diagnosis for proper treatment category and decrease the burden of the disease in the society.

\section{REFERENCES}

1. Jain MC: Leprosy scenario in Nepal. J Nepal Med Assoc. 2008;47:260-63.

2. Mathur MC, Ghimire RBK, Shrestha P, Kedia SK: Clinicohistopathological Correlation in leprosy. Kathmandu Univ Med J. 2011;36:248-51.

3. Pandya AN, Tailor HJ: Clinicopathological correlation of leprosy. Indian J Dermatol Venereol Leprol. 2008;74:174-6.

4. Moorthy BN, Kumar P, Chatura KR, Chandrasekhar HR, Basavaraja PK: Histopathological correlation of skin biopsies in leprosy. Indian J Dermatol Venereol Leprol. 2001;67:299-301.

5. Kar PK, Arora PN: Clinicopathological study of macular lesions in leprosy. Indian J Lepr. 1994;66:435-41.

6. Jerath VP, Desai SR: Diversities in clinical and histopathological classification of Leprosy. Lepr India. 1982;54:30.

7. Jha R, Karki S: Limitations of clinic-histopathological Correlation of Skin biopsies In Leprosy. J Nepal health Res Counc. 2010;8:40-3. 8. Bhatia AS, Katoch K, Narayanan RB, Ramu G, Mukherjee A, Lavania RK: Clinical and histopathological correlation in the classification of leprosy. Int J Lepr. 1993;61:433-8.

9. Jopling WH, McDougall ACL: Handbook of leprosy,5th edition, Delhi, CBS Publishers and Distributers. 1996;10-53.

10. Harboe M: Overveiw of host parasite relations. In Hastings RC, Opromolla DVA. Eds. Leprosy, 2nd edition, new York, Churchill Livingstone, 1994: 87-112.

11. Sharma A, Sharma RK, Goswsami KC, Bardwaj S: ClinicoHistopathological Correlation in Leprosy. JK Science. 2008;10:20-4. 12. Kalla G, Salodkar A, Kachhawa D: Clinical and histopathological correlation in leprosy. Int J Lepr. 2000;68:184-5.

13. Barbosa AA Jr., Jambeiro J, Cirqueira JSO, Silva TC: Retrospective histopathological classification of 1,108skin biopsies from patients clinically suspected of having leprosy from Bahia, Northeast Brazil. Rev Soc Bras Med Trop. 1998;31:533-7.

14. Singhi MK, Kachhawa D, Ghiya BC: A retrospective study of clinico-histopathological correlation in leprosy. Indian J Pathol Microbiol. 2003;46:47-8.

15. Chacko CJG: Role of histopathology in the early diagnosis of leprosy. Indian J Lepr. 1993;65:23-27.

Copyright by Deeptara Pathak Thapa, et al. This is an open access article distributed under the terms of the Creative Commons Attribution License, which permits unrestricted use, distribution, and reproduction in any medium, provided the original author and source are credited. 